\title{
Dramaturgia expandida: processo de significação das imagens em movimento
}

Dorotea Souza Bastos, Centro Multidisciplinar de Santa Maria da Vitória, Universidade Federal do Oeste da Bahia, Santa Maria da Vitória, BA; E-mail: <doroteabastos@gmail.com>.

Resumo

Este artigo trata da apresentação da pesquisa de doutoramento atualmente realizada na Universidade do Alvarge em conjunto com a Universidade Aberta de Portugal, que constitui uma possibilidade investigativa a respeito das questões que envolvem a imagem técnica do cinema, especialmente no que diz respeito à criação de dramaturgias, a partir do encontro da imagem em movimento com as novas tecnologias.

Nesta investigação, o ato representacional da imagem é visto como processo de significação no cinema, a partir da expansão lógica da dramaturgia que é tratada como geradora de relações que compõem a cena.

O processo de criação que leva ao desenvolvimento dessas relações expande as fronteiras da arte e das tecnologias utilizadas para gerar um produto híbrido, cuja dramaturgia original só existe se a relação de expansão de fronteiras também existir.

A dramaturgia é, portanto, no contexto apresentado nesta investigação, a tessitura da cena, sendo a imagem um "mecanismo" de narrativa que compõe a dramaturgia, possibilitando novas possibilidades estéticas e poéticas de criação.

Palavras-chave: Cinema, Dramaturgia, Imagem, Narrativa.

\section{Expandindo a arte dramatúrgica}

Desde o pensamento aristotélico, a dramaturgia diz respeito à composição de um drama, sendo que a palavra "dramaturgia" esteve sempre relacionada à ideia de organização de peças de teatro. Segundo Patrice Pavis, em sentido amplo, a dramaturgia diz respeito à "técnica (ou a poética) da arte 
dramática, que procura estabelecer os princípios de construção da obra" (Pavis, 2005: 113).

Pavis comenta que, até o período clássico, a dramaturgia era elaborada pelos autores das peças teatrais como uma forma de compilar um conjunto de regras para compor uma peça.

Porém, a dramaturgia clássica estava pautada unicamente no trabalho autoral e com a preocupação da narrativa da peça teatral, não voltando a atenção à realização cênica do espetáculo (Pavis, 2005).

A noção de dramaturgia foi tomando outros contornos a partir de pesquisas como as do dramaturgo alemão Bertold Brecht, que, ainda no início do século $X X$, desenvolve o conceito de teatro épico, o que ampliou o próprio conceito de dramaturgia.

Se, no sentido original, a dramaturgia estava relacionada apenas ao texto narrativo da obra teatral, no sentido brechtiano, ela abrangia não só o texto original como também os elementos cênicos utilizados para compor a peça. Isso ocorre porque se desloca a ideia de representação ilustrativa do texto, abrindo espaço para a adaptação, e a linguagem verbal passa a ser linguagem teatral, que é a linguagem de atuação também no cinema. Segundo Ana Pais,
apesar de manter uma certa primazia, na medida em que se mantém como elemento-base do espetáculo, o texto da dramaturgia brechtiana vê-se desobrigado de uma autoria intocável, passando a ser apropriado por outra voz, que nele projecta a sua visão (Pais, 2004: 37).

Com influência do teatro, mas com a presença do dispositivo tecnológico, no cinema, a narrativa é formada a partir das imagens em movimento que se configuram em unidades de composição dramatúrgica. Ou seja, em sentido amplo, a dramaturgia no cinema está relacionada à construção de uma ação e não apenas ao envolvimento com um evento central que gesta a organização das cenas.

Nesta acepção, considera-se dramaturgia não apenas os elementos isolados, mas também o vínculo entre a forma e 
conteúdo apresentados, pois "existe o texto, aquilo que ele exprime e sugere; mas existe também um além-do-texto" (Roubine, 1998: 62). Pode-se assim dizer que a dramaturgia, também no cinema, ultrapassa o mero estudo do texto e engloba a realização cênica, o que inclui a montagem, escolha dos espaços cênicos, o trabalho com os elementos das visualidades da cena, até a interpretação dos atores. Ou seja, neste caso, a dramaturgia trata dos mecanismos necessários à narrativa, aos quais também incluímos a própria cinematografia, envolvendo as escolhas de diretores de fotografia, o uso de figurinos, adereços, iluminações, os componentes das visualidades da cena.

Pavis também aponta que o objetivo da dramaturgia é "representar o mundo, seja sob a ótica de um realismo mimético, seja quando toma distância em relação à mimese, contentando-se em figurar um universo autônomo" (Pavis, 2005: 114). Pavis complementa que "a tarefa final e principal será efetuar o "ajuste" entre texto e cena, decidir de que forma interpretar o texto, como dar-lhe um impulso cênico que o esclareça para determina época e determinado público" (Pavis, 2005: 113).

Desta forma, a dramaturgia está ligada diretamente à ação, que, segundo Renata Pallottini, "no sentido dramático, não é sinônimo de ato físico. Ação é tudo aquilo que impulsiona a máquina do drama para a frente, tudo aquilo que muda a situação, produzindo, portanto, movimento" (Pallottini, 1989: 71).

Sendo a ação cinematográfica apresentada através de imagens a partir de relações de sentido em que se configura a possibilidade polissêmica da dramaturgia e que abrange os modos de estruturar os sentidos do espetáculo - e, neste caso, na criação das imagens em movimento - é possível, no cinema, conceber a ideia de uma dramaturgia em seu sentido expandido, para além da mera apreciação textual, enfatizando e colocando, no discurso imagético, o processo criativo 
envolvido na obra e que sugere e cria uma narrativa a partir da imagem.

Esta expansão é possível, também, devido à utilização das novas tecnologias, que permitem, por exemplo, o acesso do público não apenas como espectador, mas como coautor da obra. Segundo Manovich (2001), essas novas tecnologias digitais ou novas mídias possuem características que permitem uma aproximação do fazer artístico, o que reconfigura a experiência estética.

O autor explica que a nova mídia é interativa e que,

ao contrário das mídias antigas, nas quais a ordem da apresentação é fixa, o usuário pode agora interagir com um objeto midiático. No processo de interação o usuário pode escolher quais elementos mostrar ou quais caminhos seguir" (Manovich, 2001: 49),

o que gera um trabalho único em que o usuário torna-se coautor da obra, gerando uma dramaturgia que se expande para além dos roteiros prévios, gerando uma relação dialógica em que o sentido se complexifica a partir do encontro da imagem com o agente modificador, que, neste caso, é o público.

A imagem, aqui, é apresentada como a menor unidade de composição da narrativa e gera uma dramaturgia que antes só era entendida tendo como ponto de partida o texto e que proporciona uma lógica, conforme Pais explica quando afirma que

fazer a dramaturgia de um espetáculo significa frequentemente estruturá-lo, dar um eixo organizador ou uma concepção particular ao que se quer dizer, ou dar a ver, podendo seguir os mais variados critérios (desde a narratividade aristotélica à fragmentação, à sobreposição de cenas simultâneas, etc.). [...] Ao escolher ou fazer opções relativamente aos materiais cênicos e à sua articulação na cena, o olhar artístico estrutura-os dramaturgicamente, fundamentando essas opções e criando uma lógica e uma coerência própria a cada espetáculo (Pais, 2004: 35). 


\section{O discurso da imagem}

O conceito de imagem foi sendo definido, modificado, problematizado e complexificado, e o que fica dessas diversas interpretações parece ser o cerne da questão: a imagem enquanto representação de algo que depende da organização de determinados elementos internos e externos para que aconteça o que Vilém Flusser (2001) já denominava de "magia".

Para Flusser, “imagens são superfícies que pretendem representar algo. Na maioria dos casos, algo que se encontra lá fora no espaço e no tempo" (Flusser, 2011: 21). Segundo Jacques Aumont, a questão da representação associada à imagem diz respeito a uma forma de analogia, sendo toda representação uma convenção. Porém o autor sugere que o ato representacional não seja visto apenas "como resultado a ser apreciado por um espectador, mas sim como processo, produção, a ser obtido por um criador" (Aumont, 2012: 206).

Se levarmos em consideração que a representação pressupõe a existência de um objeto - a coisa a ser representada - é possível identificar que a realidade precede a imagem. Esse aspecto de vivência da imagem pode ser observado a partir das técnicas figurativas que é descrito por Edmond Couchot como morfogênese por projeção. Segundo Couchot, "pode-se chamar a lógica figurativa ótica de uma morfogênese por projeção. [...] A morfogênese por projeção implica sempre a presença de um objeto real preexistente à imagem." (Couchot, 2011: 39). Ou seja, esta relação

cria uma relação biunívoca entre o real e sua imagem. A imagem se dá, então, como representação do real. A imagem traz do real a marca luminosa, permanente, morfogeneticamente estável, capaz de perdurar no tempo a ser apresentada de novo - re-presentada indefinidamente. A imagem estabelece uma junção entre dois momentos do tempo, aquele em que foi captada (feita à mão ou registrada automaticamente pela câmera fotográfica) e aquele em que é contemplada (Couchot, 2011: 39-40). 
A lógica figurativa ótica homogeneíza o espaço e o tempo, alinhando a imagem, o objeto representado e o sujeito. Esta ideia dialoga com Flusser, quando apresenta as imagens como "resultado do esforço de se abstrair duas das quatro dimensões espácio-temporais, para que se conservem apenas as dimensões do plano" (Flusser, 2011: 21). Flusser ainda acrescenta que as imagens são símbolos conotativos, não sendo um "conjunto de símbolos com significados inequívocos" (Flusser, 2011: 22). Dessa forma, o conceito de Flusser dialoga com a ideia de uma imagem no cinema que vai além da mera representação por imitação e que gera dramaturgia, a que chamamos, aqui, de "dramaturgia expandida".

Josep Domènech, pesquisador dos estudos visuais, discorre sobre a necessidade de compreender que as imagens não são naturais e que não necessariamente estas terão algum tipo de vínculo com a realidade, ou seja, as escolhas imagéticas realizadas para o filme não necessariamente vão gerar um produto verossímil a partir da repetição. Para Domènech, a imagem "é uma construção que se superpõe à realidade e sintetiza a ambivalência deste em uma direção determinada" (Domènech, 2011: 15) e, no caso do cinema, por sua característica midiática, a imagem gerada é uma imagem técnica.

Segundo Flusser, uma imagem técnica é uma imagem produzida por aparelhos. O autor explica que, sendo o aparelho um produto de uma técnica, estamos tratando de um "texto científico aplicado" (Flusser, 2011: 29).

Flusser complementa que as "imagens técnicas são, portanto, produtos indiretos de textos - o que lhes confere posição histórica e ontológica diferentes das imagens tradicionais" (Flusser, 2011: 29). Essas diferenças nas posições histórica e ontológica da imagem podem ser descritas a partir de algumas características apontadas por Flusser, que apresenta a imagem técnica como pós-histórica e que, ao contrário da imagem tradicional, não precede o texto, mas o sucede. Além disso, a 
imagem técnica, em sua ontologia, já não imagina o mundo como a imagem tradicional, mas imaginam textos que concebem imagens que imaginam o mundo, o que nos remete à ideia dramatúrgica, a partir da leitura do discurso imagético.

Assim como para Flusser, também para Domènech, a era das imagens técnicas teve início com o surgimento da fotografia, "ainda que na verdade todas as imagens tenham sido confeccionadas por meio de uma técnica ou de outra" (Domènech, 2011: 46), como é o caso dos desenhos e esculturas. Para o autor, a diferenciação que nos permite chamar de técnicas essas imagens após a invenção da fotografia é a relação e a possibilidade de intervenção do dispositivo tecnológico no qual a imagem fora produzida, o que corrobora o conceito de imagem técnica de Flusser.

Domènech traz a essa discussão a existência de um meio que permite um processo diferenciado na criação dessas imagens técnicas: o meio industrial. Segundo o autor, estes meios industriais "implicam o uso de uma nova estrutura tecnológica e novas formas de produção e consumo que determinam a forma das imagens que geram" (Domènech, 2011: 47).

Esta ideia é também comentada por Arlindo Machado (2010), quando trata dos conceitos trazidos por Flusser. Para estes autores, o que é visto ao contemplar as imagens produzidas por aparelhos não é o "mundo", mas determinados conceitos relativos ao mundo. Machado ainda comenta que, provavelmente, só com a chegada dos computadores e, consequentemente, das imagens digitais, as imagens técnicas puderam se revelar mais abertamente "como resultado de um processo de codificação icônica de determinados conceitos científicos" (Machado, 2010: 47). Sobre o mundo a ser representado pela imagem, Flusser afirma que 
caráter aparentemente não-simbólico, objetivo, das imagens técnicas faz com que seu observador as olhe como se fossem janelas e não imagens. O observador confia nas imagens técnicas tanto quanto confia em seus próprios olhos" (Flusser, 2011: 30).

Flusser aponta a necessidade de ver a imagem técnica como um símbolo, assim como o são todas as imagens - inclusive as tradicionais. Segundo o autor, as imagens técnicas codificam textos em imagens, ou seja, são metacódigos de textos e seu deciframento é a reconstrução de texto que a imagem significa. Apesar de se reportar mais diretamente à fotografia, os conceitos trazidos por Flusser expandem-se a outros tipos de imagens técnicas, como as do cinema (imagens em movimento) e as imagens digitais (estáticas ou em movimento).

A imagem, no contexto da cena, vira uma espécie de escrita para a ação e faz com que "essa escrita cênica, de uma forma autônoma e específica, seja um meio de expressão" (Cintra, 2010: 90). Segundo Wagner Cintra, esse componente visual, apesar de estruturado, não encontra sua autonomia e completude apenas na imagem.

Segundo o autor, "essa estrutura visual, no plano cênico, emergirá como uma realidade dramatúrgica própria e verdadeira. Essa estrutura dramática traduz, por meio da imagem apresentada, níveis desconhecidos da realidade." (Cintra, 2010: 91).

\section{Considerações}

Reconhecer os aspectos que se entrelaçam nas relações entre dramaturgia e as imagens em movimento é buscar novos olhares para a questão do discurso imagético no cinema e o conceito de imagem trazido por Flusser é o ponto fulcral para esta discussão.

O simbólico faz parte do cinema e a dramaturgia gerada a partir das imagens (que também são simbólicas) permitem o 
que Flusser denomina abstração de terceiro grau, própria das imagens técnicas. Segundo Katia Maciel, "o cinema [..] ainda é o universo de um determinado tipo de representação ligada à ilusão, e, portanto, é uma expressão da imaginação" (Maciel, 2011: 253).

Nesse contexto, a dramaturgia se apresenta como geradora de relações que compõem a cena do cinema a partir da produção de significados com base no discurso das imagens, uma vez que estas imagens fazem parte do conjunto de eleições estéticas e ideológicas que formam o filme.

Uma dramaturgia relacionada ao discurso da imagem também está relacionada ao movimento de criação cênica voltado à própria imagem, não mais à representação de um personagem escrito em um roteiro, mas o hibridismo entre corpo, texto e elementos visuais, intensificado com o uso de novas tecnologias e meios de comunicação.

Neste ponto, a dramaturgia se expande para além da mera execução tecnicista, que busca uma representação por imitação e apresenta aspectos de criação, a partir da poética das imagens capazes de produzir narrativas de construção simbólica de forma que a dramaturgia se torna a própria tessitura da cena.

\section{Referências}

AUMONT, J. (2012). A Imagem. Campinas, SP: Papirus Editora.

CINTRA, W. (2010, Julho). A dramaturgia da imagem no teatro de Tadeusz Kantor. In: REBENTO - Revista de Artes do Espetáculo, no2. São Paulo, SP: Instituto de Artes.

COUCHOT, E. (2011). Da representação à simulação. In: PARENTE, André (org.). Imagem-Máquina: a era das tecnologias do virtual. São Paulo, SP: Editora 34.

DOMÈNECH, J. (2011). A forma do real: introdução aos estudos visuais. São Paulo, SP: Summus. 
FLUSSER, V. (2011). Filosofia da caixa preta. Ensaios para uma futura filosofia da fotografia. São Paulo, SP: Annablume.

MACHADO, A. (2010). Arte e mídia. $3^{\underline{a}}$ edição. Rio de Janeiro, RJ: Jorge Zahar.

MACIEL, K. (2011). A última imagem. In: PARENTE, André (org.). Imagem-Máquina: a era das tecnologias do virtual. São Paulo, SP:

Editora 34.

MANOVICH, L. (2001). The language of new media. Cambridge: The MIT Press.

PAIS, A. (2004). O discurso da cumplicidade: dramaturgias contemporâneas. Lisboa: Edições Colibri.

PALLOTINNI, R. (1989). Dramaturgia - A construção do personagem. São Paulo, SP: Editora Ática.

PAVIS, P. (2005). Dicionário de teatro. São Paulo, SP: Perspectiva.

ROUBINE, J. (1998). A linguagem da encenação teatral. Rio de Janeiro, RJ: Jorge Zahar. 